Research Article

\title{
Experimental Study on Influence of Joint Surface Morphology on Strength and Deformation of Nonthrough Jointed Rock Masses under Direct Shear
}

\author{
Yuanming Liu (D, Qingzhi Chen, Huiyu Chen, Xun Ou, Dafu Wu, and Xingchao Tian \\ School of Civil Engineering, Guizhou University, Guiyang 550003, Guizhou, China \\ Correspondence should be addressed to Yuanming Liu; 845612605@qq.com
}

Received 19 April 2021; Revised 18 June 2021; Accepted 30 June 2021; Published 9 July 2021

Academic Editor: Rihong Cao

Copyright (c) 2021 Yuanming Liu et al. This is an open access article distributed under the Creative Commons Attribution License, which permits unrestricted use, distribution, and reproduction in any medium, provided the original work is properly cited.

\begin{abstract}
Direct shear tests were carried out on nonthrough jointed rock masses (NTJRM) with three types of joints under five normal stresses. The strength characteristics of shear strength, initial crack strength, and residual strength and the deformation characteristics of tangential displacement and dilatancy displacement as well as the transformation of failure mode and the variation of shear parameters of rock mass with different joint morphology are studied. Under the same normal stress, with the increase of joint undulation, the shear strength of NTJRM increases, and the corresponding tangential displacement of NTJRM increases. Two typical failure modes are observed: TTTS mode and TSSS mode. TTTS model indicates that the initial failure, extension failure, and final failure of rock mass are caused by tensile action, while the failure mode of through plane is formed by shear action. The initial failure of TSSS mode rock mass is caused by tensile action, while the expansion and final failure are caused by shear action, and the failure mode of through plane is formed under shear action. When the joint undulation is small and the normal stress is small, NTJRM will fail in TTTS mode; when the joint undulation is large and the normal stress is large, NTJRM will fail in TSSS mode. The results show that the shear parameters of NTJRM are related to the joint morphology, the bond force increases with the increase of joint undulation, and the internal friction angle increases with the increase of joint undulation. The research results of direct shear test of nonthrough jointed rock mass can provide reference for related research.
\end{abstract}

\section{Introduction}

Jointed rock mass is a familiar complex engineering-geological body in nature [1], in which the joint plays an essential role in reducing the rock mass strength [2-4]. The close association between internal joints coalescence and failure in rock engineering has been proven by various studies [5-8]. Generally, the jointed rock mass can be classified into nonthrough jointed rock mass (NTJRM) and through jointed rock mass (TJRM) according to the connectivity of joint. And, the failure mechanism of NTJRM is different from NTJRM. Therefore, it is of great significance to investigate the shear strength and failure characteristics of NTJRM. A number of researches have been carried out to understand the influence of different joint geometry parameters on the mechanical behavior of NTJRM. For instance, Bobet and Einstein [9] investigated the failure modes of specimens with two different types of joints under uniaxial loading. Wong and Chau [10] performed uniaxial loading tests on rock-like specimens containing double joints and summarized the relationship between failure modes and joint angles and rock bridges.

Recently, more attention has been drawn to study crack propagation. Morgan and Einstein [11] used shale containing natural bedding plane to fabricate specimens and found that the cracks at the joint tips usually grow along the bedding plane. Alneasan et al. [12] theoretically analyzed the propagation of inclined interface cracks in two different rock layers under both compression and tension. Wang et al. [13] utilized artificial layered rock mass with a single joint using 
cement mortar material to analyze the influences of the bedding plane and joint on the mechanical characteristics. Cao et al. $[14,15]$ conducted experimental and numerical compression-shear tests on double-notched specimens to investigate the fracturing characteristics of transversely isotropic rock under planar shear fracture loading. Zhang et al. [16] studied the propagation mechanism of an oblique straight crack and revealed its mechanical characteristics under in-plane biaxial compression. Lin et al. [17, 18] performed uniaxial compression tests on jointed rock-like specimens with two dissimilar layers. Fan et al. [19] used the PFC program to establish numerical models containing one open flaw and two circular openings. The digital image correlation (DIC) techniques are employed to study the crack coalescence process of specimens with two dissimilar layers under uniaxial loading [20, 21].

Direct shear test is one of the effective methods to study the effect of shear stress on jointed rock mass, which can simulate the shear stress state of jointed rock mass. Lajtai $[22,23]$ studied the failure mode of jointed plaster by direct shear test, in which the failure modes of jointed plaster are sorted into three types: tensile failure, shear failure, and crushing failure. Chen et al. [24], Qin et al. [25], and Heng et al. [26] have studied the failure characteristics of rock mass with nonthrough joints under different connectivity and normal stress. Zhao et al. [27] used PFC software to study the deformation and failure mode of jointed rock mass. Wang et al. [28] carried out numerical analysis on the scale effect of elasticity, strength, and failure mode of jointed rock mass. Chen et al. [29] conducted direct shear tests on NTJRM with different connection rates to study their shear failure process and strength characteristics. Numerical methods are another effective method to study the strength and deformation characteristics of NTJRM under shear test.

It is generally known that joint morphology has an important influence on the strength and deformation characteristics of jointed rock mass. But the influence of joint morphology on the strength and deformation of NTJRM is not considered in the above studies. Only several scholars have considered the influence of joint morphology and conducted direct shear tests. Wang et al. [30] and Ma et al. [31] studied the effect of joint morphology on shear behavior of joints. Liu and Xia [32] proposed the failure mode of NTJRM. Liu et al. [33] and Chen et al. [34] studied the influence of joint morphology on the shear strength of NTJRM.

In this study, the influence of joint surface morphology on the strength and deformation characteristics of NTJRM is studied by direct shear test, and the variation of shear parameters with joint morphology is studied. The relationship between failure mode and joint surface morphology of NTJRM is investigated. The failure mode of NTJRM in direct shear test can provide experimental verification for numerical simulation.

\section{Material and Method}

2.1. Preparation of Specimens. Rock-like materials are used to prepare rock mass specimens with discontinuous joints. The rock-like material used in this experiment is cement mortar with a mixing ratio of sand: cement $:$ water $=3: 2: 1$ (the sand is dug from a river in Shanghai area). The length $\times$ width $\times$ thickness of the NTJRM specimens is $300 \mathrm{~mm} \times 300 \mathrm{~mm} \times 150 \mathrm{~mm}$. The joints had serrated morphology, a connection rate of 0.53 , and undulation angles of $0^{\circ}, 15^{\circ}$, and $30^{\circ}$. The size of the specimens is shown in Figure 1.

As shown in Figure 2, a self-made wooden mold was used to prepare the specimens. Serrated joints with undulation angles of $0^{\circ}, 15^{\circ}$, and $30^{\circ}$ were prepared by inserting thin steel sheets of $0.3 \mathrm{~mm}$ thickness into the poured specimens. The steel sheets were drawn out before the initial setting of the specimens.

2.2. Physical and Mechanical Properties of the Specimens. The physical and mechanical property parameters of the rock bridge section of the NTJRM are listed in Table 1. The shear parameters of the serrated joints are summarized in Table 2. All the mechanical property is obtained in the compressive and tensile strength test. The corresponding specimens after the compressive and the tensile test are demonstrated in Figures 3 and 4, respectively.

2.3. The Instruments Used in This Test. As shown in Figure 5, the specimen was installed in the rock mass direct shear apparatus, which is composed of the main engine, a hydraulic system, a servocontrol system, and a computerized control and treatment system. The main technical parameters of this rock mass direct shear apparatus are given as follows:(1) the maximum normal load is $500 \mathrm{kN}$, with a measurement accuracy of $\pm 1 \%$; (2) the maximum tangential load is $1000 \mathrm{kN}$, with a measurement accuracy of $\pm 1 \%$; (3) the measurement range of normal deformation is $0 \sim 20 \mathrm{~mm}$, and the measurement accuracy of normal load deformation is $\pm 0.5 \%$ F.S; (4) the measurement range of tangential deformation is $0 \sim 50 \mathrm{~mm}$, and the measurement accuracy of tangential load deformation is $\pm 0.5 \%$ F.S; (5) output pressure of hydraulic station is $\leq 21 \mathrm{MPa}$; (6) deformation rate is $0.05 \sim 50.0 \mathrm{~mm} / \mathrm{min}$.

2.4. The Testing Procedure. The specimens were divided into three groups for serrated joints with undulation angles of $0^{\circ}$, $15^{\circ}$, and $30^{\circ}$. In each group, the direct shear tests were carried out under five different normal stress levels $(0.5 \mathrm{MPa}$, 1.0 MPa, 1.5 $\mathrm{MPa}, 2.0 \mathrm{MPa}$, and 3.0 MPa). During the direct shear test, the normal load was controlled by load, while the tangential load is controlled by displacement. Under the normal stress test mode, the normal stress was first loaded to the set value and then the shear stress is applied. After the normal load servo was stable, the horizontal load was then applied at a rate of $0.01 \mathrm{~mm} / \mathrm{s}$. The relevant data, including normal load, normal displacement, tangential load, and tangential displacement, were collected automatically by the computer.

In addition, an external monitoring system containing a camera was installed beside the testing machine to monitor 


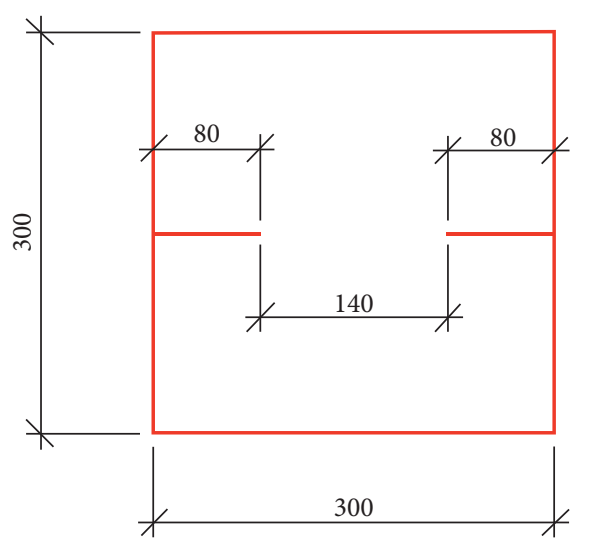

(a)

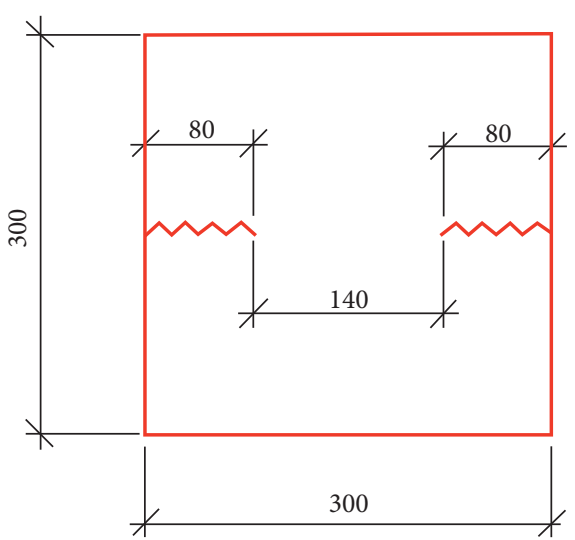

(b)

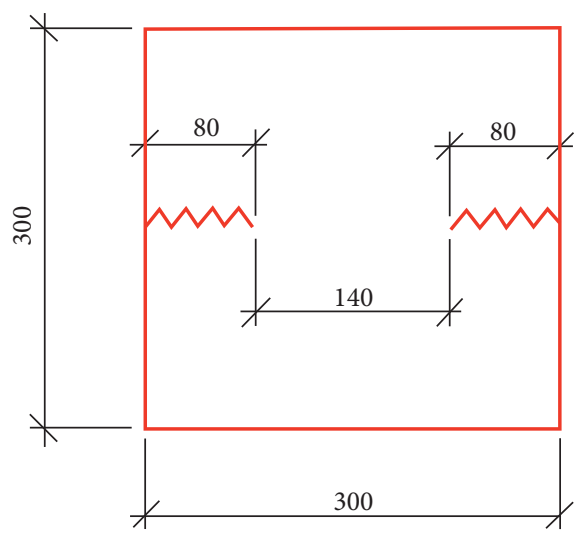

(c)

FIGURE 1: Specimens of rock mass with discontinuous joints. (a) $\alpha=0^{\circ}$. (b) $\alpha=15^{\circ}$. (c) $\alpha=30^{\circ}$.

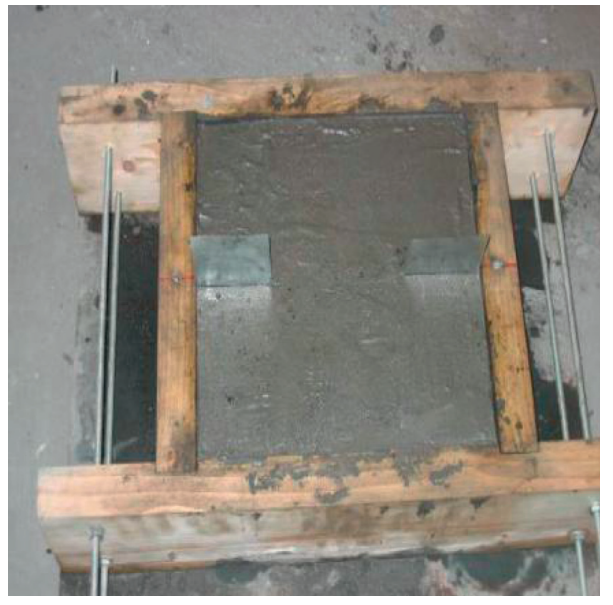

(a)

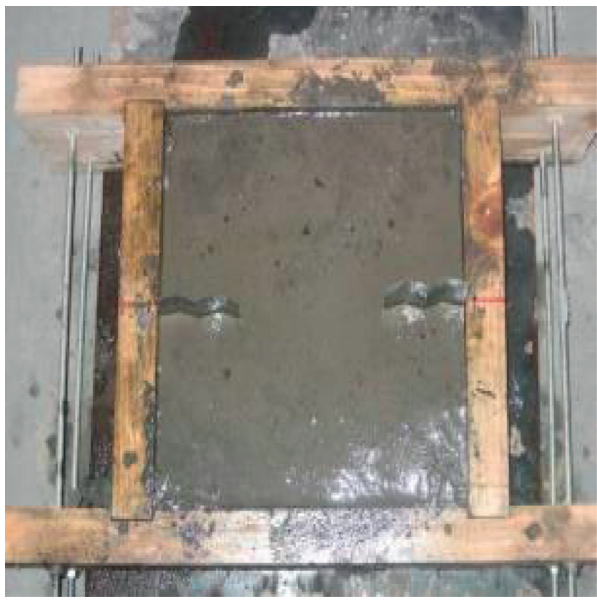

(b)

Figure 2: Continued. 


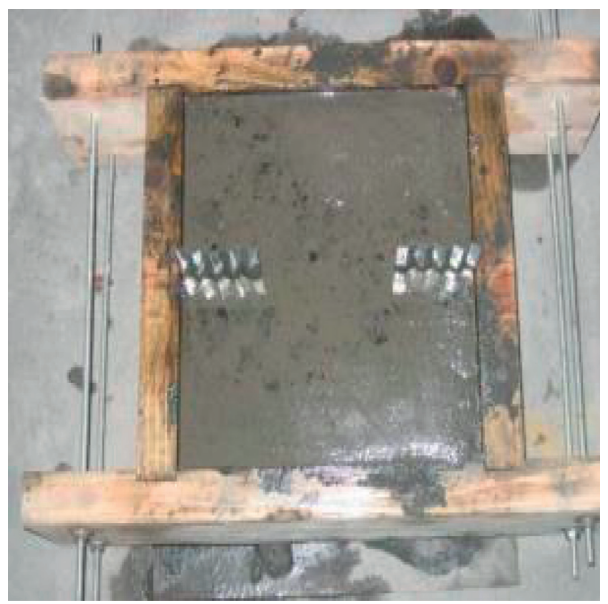

(c)

Figure 2: Preparation process of specimens with different undulation angles. (a) Specimen with undulation angle of $0^{\circ}$. (b) Specimen with undulation angle of $15^{\circ}$. (c) Specimen with undulation angle of $30^{\circ}$.

TABLE 1: Physical and mechanical property parameters of the rock bridges.

\begin{tabular}{|c|c|c|c|c|c|c|}
\hline $\begin{array}{l}\text { Density } \\
\left(\mathrm{g} / \mathrm{cm}^{3}\right)\end{array}$ & $\begin{array}{l}\text { Compressive } \\
\text { strength }(\mathrm{MPa})\end{array}$ & $\begin{array}{c}\text { Tensile } \\
\text { strength }(\mathrm{MPa})\end{array}$ & $\begin{array}{c}\text { Modulus of } \\
\text { elasticity }(\mathrm{GPa})\end{array}$ & Poisson's ratio & Cohesion (MPa) & $\begin{array}{l}\text { Angle of internal } \\
\text { friction }\left({ }^{\circ}\right)\end{array}$ \\
\hline 2.10 & 18.0 & 1.71 & 3.70 & 0.16 & 3.93 & 41.6 \\
\hline
\end{tabular}

TABLE 2: Shear parameters of serrated joints.

\begin{tabular}{lcc}
\hline The undulation angle $\left(^{\circ}\right)$ & Cohesion $(\mathrm{MPa})$ & Angle of internal friction $\left(^{\circ}\right)$ \\
\hline 0 & 0.56 & 32.3 \\
15 & 0.56 & 47.3 \\
30 & 0.56 & 62.3 \\
\hline
\end{tabular}

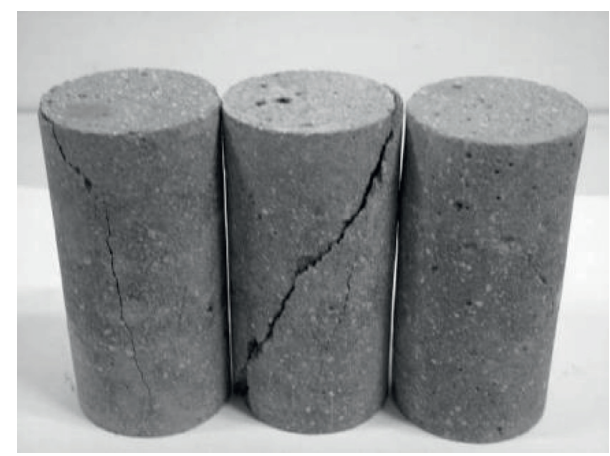

FIGURE 3: Specimens after the compressive strength test.

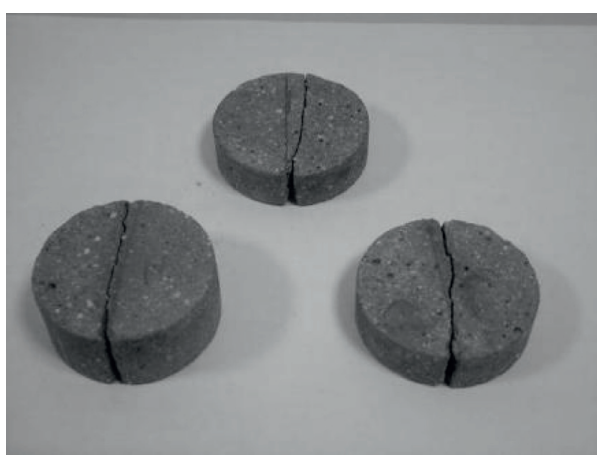

FIGURE 4: Specimens after the tensile strength test. the initiation and propagation of the crack at the end of the joint and record the time when the initial crack appeared.

\section{Results and Discussions}

\subsection{Deformation Characteristics of Rock Specimens during the Test}

3.1.1. Normal Deformation of Rock Specimens. It can be seen from Figure 6 [33] that the normal deformation curve of
NTJRM is similar to the normal deformation curve of joints, and both of them are approximately double-curving. This indicates that, under normal stress, the joints of NTJRM also undergo closed deformation. The closed deformation makes the upper and lower joint surfaces contact closely. When the tangential force is applied, friction will be generated, so that joints and rock bridges share the tangential load.

Under five levels of normal stress, the normal displacements of the specimens are shown in Table 3 and Figure 7. Obviously, the normal stress and joint surface 


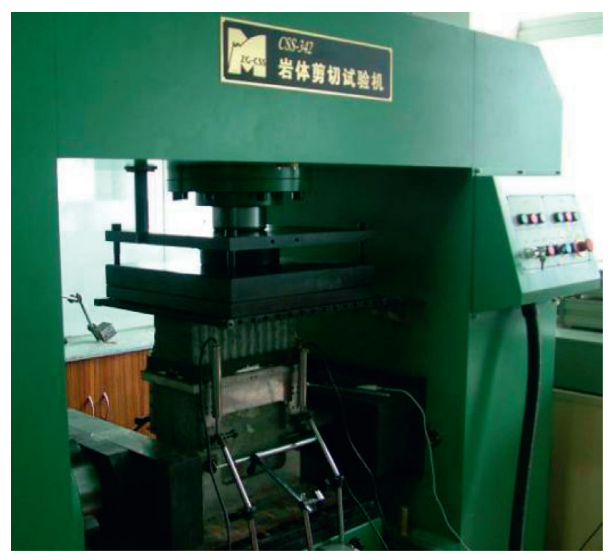

FIgURE 5: The main engine of the rock mass direct shear apparatus.
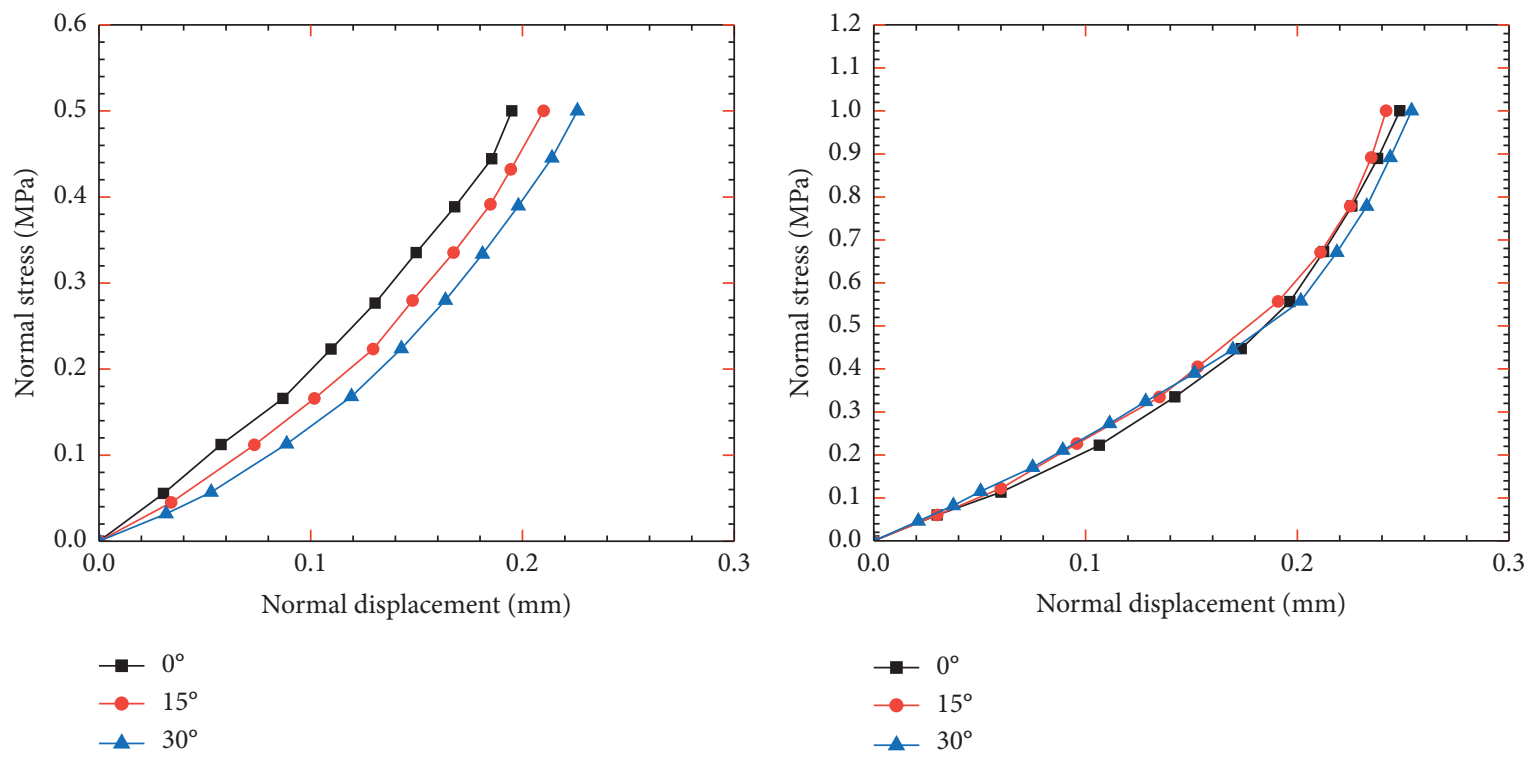

(a)

(b)
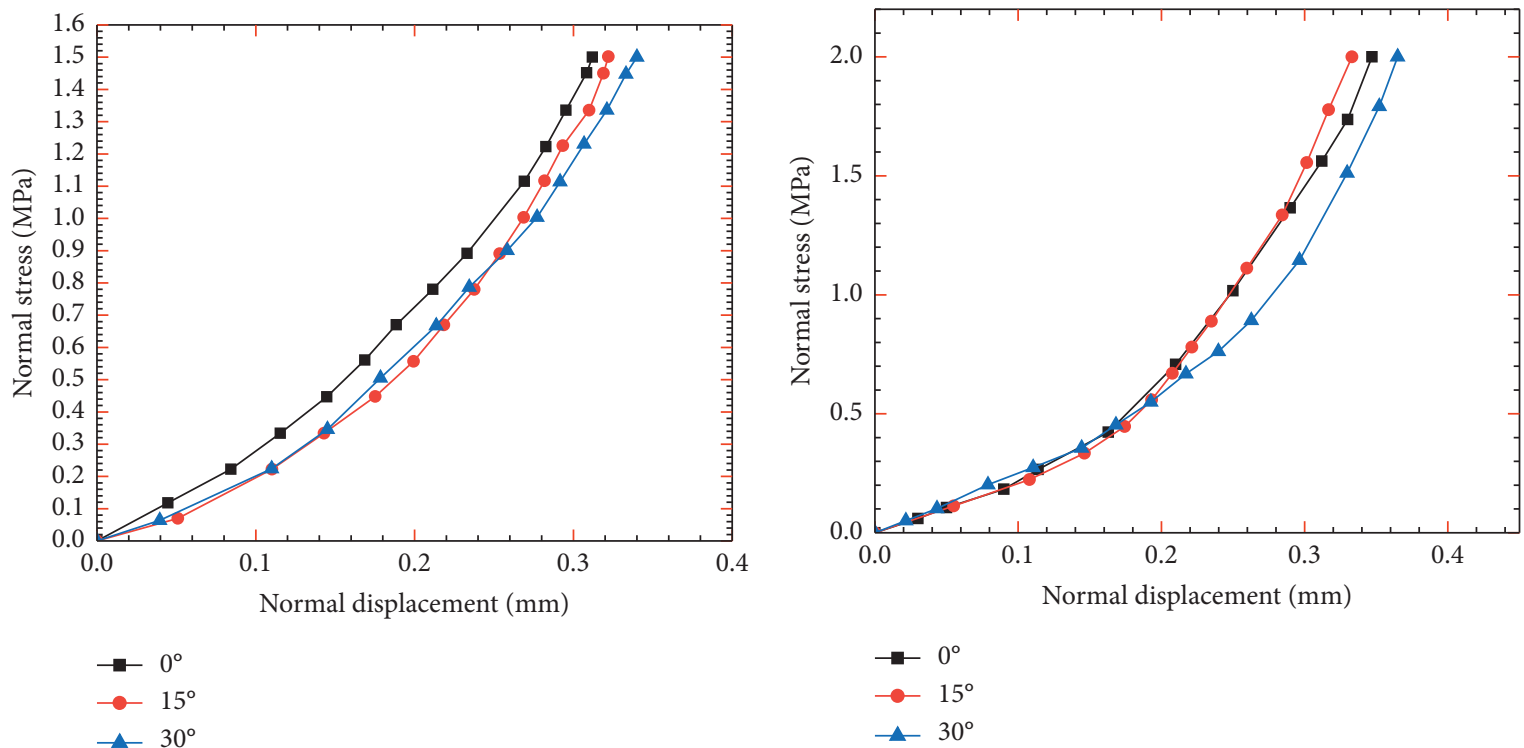

(c)

(d)

Figure 6: Continued. 


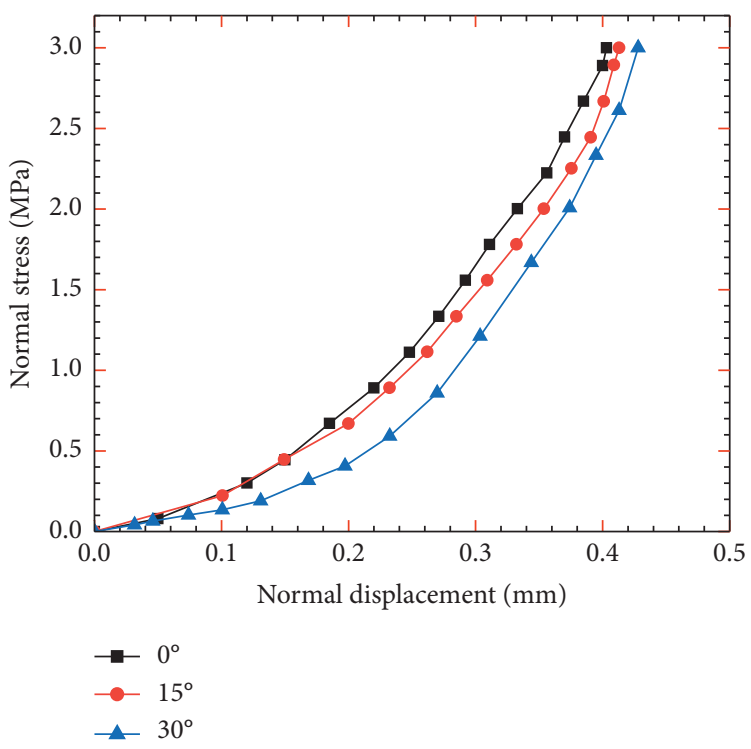

(e)

FIGURE 6: Normal deformation curve of the rock specimens (a) when the normal stress is $0.5 \mathrm{MPa}$, (b) when the normal stress is $1.0 \mathrm{MPa}$, (c) when the normal stress is $1.5 \mathrm{MPa}$, (d) when the normal stress is $2.0 \mathrm{MPa}$, and (e) when the normal stress is $3.0 \mathrm{MPa}$.

TABle 3: Peak normal displacements of specimens, unit: $\mathrm{mm}$.

\begin{tabular}{lccccc}
\hline \multirow{2}{*}{ Undulation angle } & \multicolumn{5}{c}{ Normal stress $(\mathrm{MPa})$} \\
& 0.5 & 1.0 & 1.5 & 2.0 & 3.0 \\
\hline $0^{\circ}$ & 0.20 & 0.24 & 0.31 & 0.35 & 0.41 \\
$15^{\circ}$ & 0.21 & 0.25 & 0.32 & 0.36 & 0.43 \\
$30^{\circ}$ & 0.23 & 0.26 & 0.34 & 0.37 & 0.44 \\
\hline
\end{tabular}

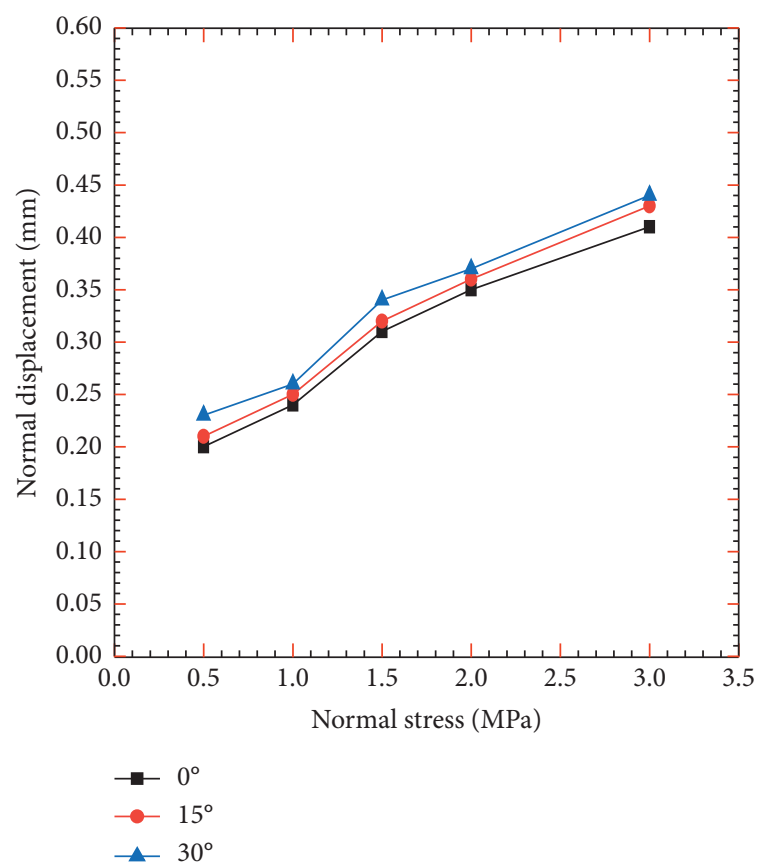

Figure 7: Normal displacement of the rock specimens. morphology have significant influence on the normal deformation of rock mass with discontinuous joints. Firstly, the normal deformation increases with the increase of normal stress. Secondly, under the same normal stress condition, the normal deformation of the joint changes with the surface morphology of the joint. The larger the undulation angle, the greater the normal displacement.

3.1.2. Tangential Deformation of the Rock Specimens. Under five different levels of normal stress, the curves of the tangential displacement of the specimens are shown in Figure 8. The peak tangential displacements of these rock specimens are shown in Table 4.

As shown in Figure 8(a) and Table 4, when the undulation angle of the joints is $0^{\circ}$, the peak tangential displacement is $1.95 \mathrm{~mm}$ under a normal stress of $0.5 \mathrm{MPa}$ and $2.86 \mathrm{~mm}$ under a normal stress of 3.0 MPa. As shown in Figure 8(b) and Table 4, when the undulation angle of the joints is $15^{\circ}$, the peak tangential displacement is $1.89 \mathrm{~mm}$ under a normal stress of $0.5 \mathrm{MPa}$ and $2.56 \mathrm{~mm}$ under a normal stress of 3.0 MPa. As shown in Figure 8(c) and Table 4, when the undulation angle of the joints is $30^{\circ}$, the peak tangential displacement is $1.84 \mathrm{~mm}$ under a normal stress of $0.5 \mathrm{MPa}$ and $2.48 \mathrm{~mm}$ under a normal stress of 3.0 MPa. To sum up, it can be seen from the data shown in Table 4 and the curve shown in Figure 8 that, for the NTJRM with the same joint surface morphology, the larger the normal stress applied during the test, the larger the peak tangential displacement of the rock mass. Under the same normal stress, the larger the undulation angle of the serrated joints, the smaller the peak tangential displacement. It can be 


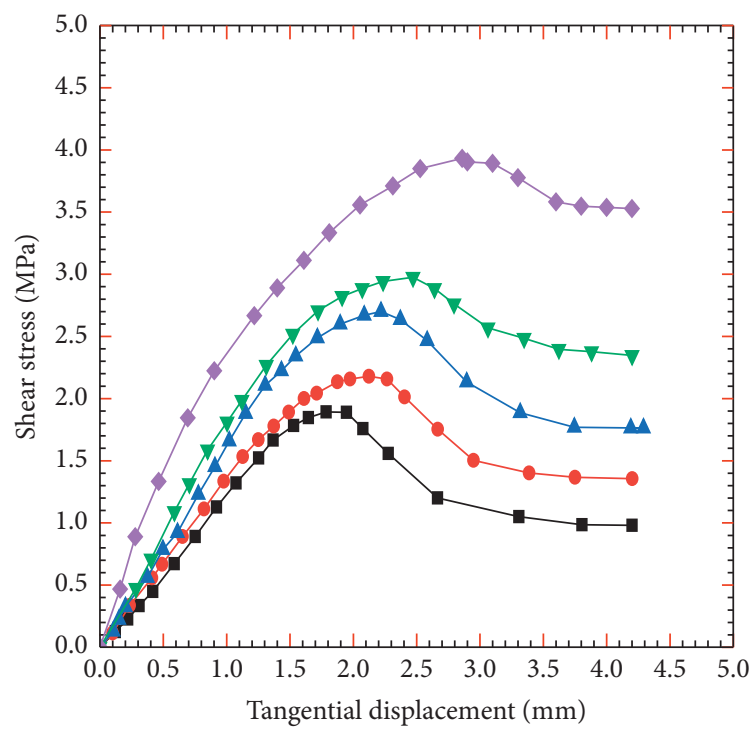

$-0.5 \mathrm{MPa}$

$\rightarrow 1.0 \mathrm{MPa}$

$-1.5 \mathrm{MPa}$

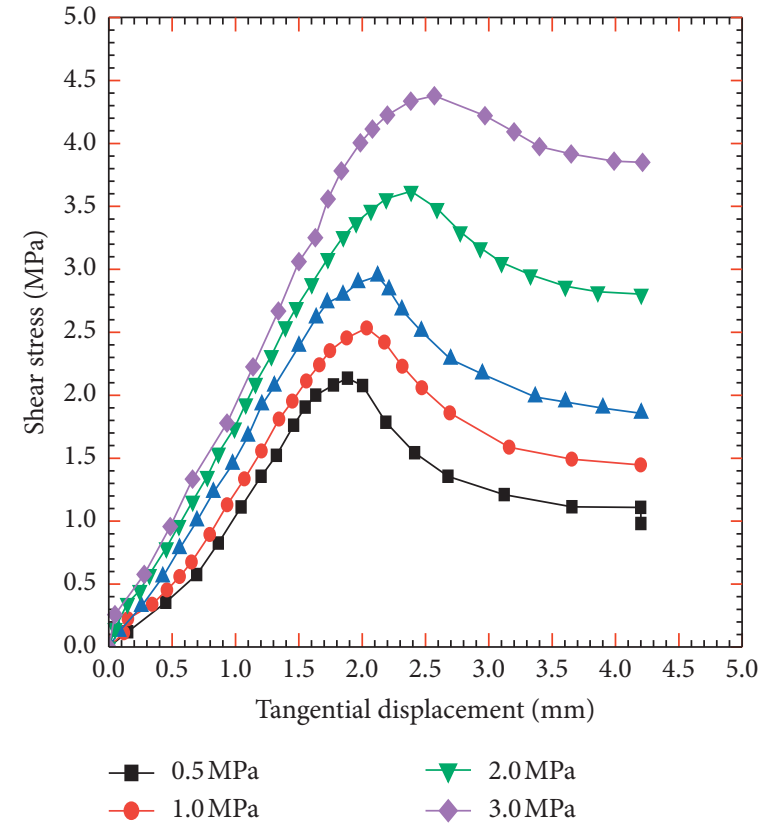

(b)
$-1.0 \mathrm{MPa}$

$-1.5 \mathrm{MPa}$

(a)

$\neg-2.0 \mathrm{MPa}$
$\neg 3.0 \mathrm{MPa}$

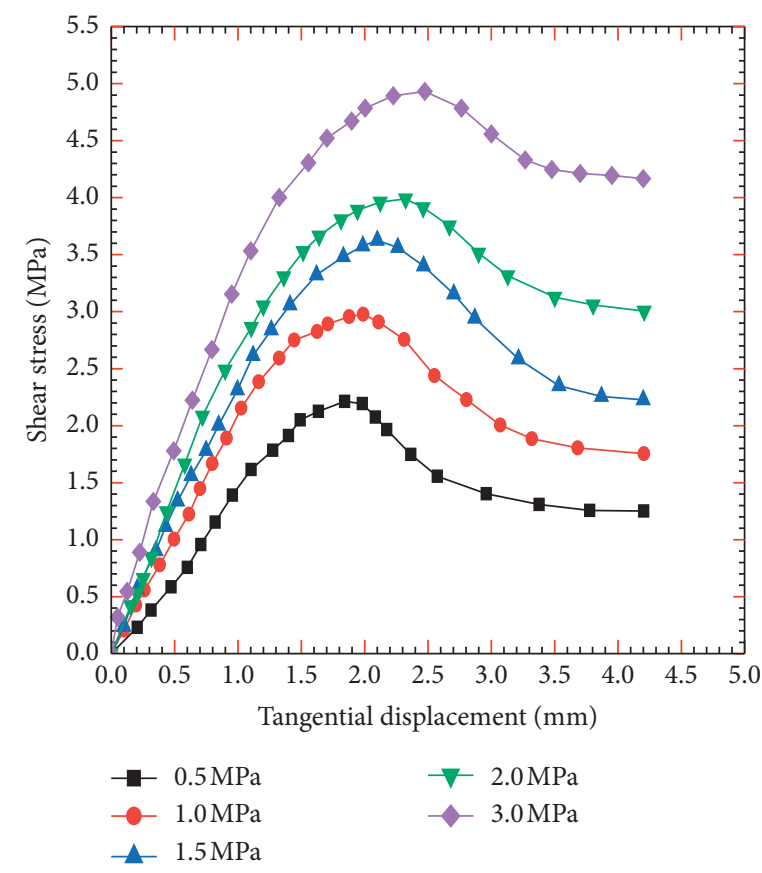

(c)

Figure 8: The curves of tangential deformation of the rock specimens (a) when the undulation angle is $0^{\circ}$, (b) when the undulation angle is $15^{\circ}$, (c) and when the undulation angle is $30^{\circ}$.

TABle 4: The peak tangential displacement of rock specimens, unit: $\mathrm{mm}$.

\begin{tabular}{lccccc}
\hline \multirow{2}{*}{ Undulation angle } & \multicolumn{4}{c}{ Normal stress (MPa) } \\
& 0.5 & 1.0 & 1.5 & 2.0 & 2.0 \\
\hline $0^{\circ}$ & 1.95 & 2.12 & 2.22 & 2.47 \\
$15^{\circ}$ & 1.89 & 2.05 & 2.01 & 2.39 & 2.57 \\
$30^{\circ}$ & 1.84 & 1.99 & 2.32 & 2.48 \\
\hline
\end{tabular}


seen that the peak tangential displacement increases with the increase of normal stress level. In addition, it can be seen from Figure 8 that the curves of tangential deformation of an NTJRM can be divided into four stages. In the first stage, the curve is slightly convex downward and the tangential stress increases rapidly with the increase of tangential displacement. In this stage, the surface of the joints appears gradually, and the folds begin to appear. In the second stage, the curve is approximately a straight line, and the tangential stress increases rapidly with the increase of tangential displacement. In the third stage, the curve is convex upward, and the tangential stress increases with the increase of tangential displacement, but the rate of increase of tangential stress is obviously lower than that of the two preceding stages. This stage exhibits the unstable extension of the new joint surface, which lasts until the rock bridge breaks. In the fourth stage, the curve is also convex downward, and the tangential stress first decreases with the increase of tangential displacement and finally tends to maintain residual strength.

3.1.3. Shear Dilatancy Deformation of the Rock Specimens. The shear dilatancy curve of the discontinuous jointed rock mass with the undulation angles of $0^{\circ}, 15^{\circ}$, and $30^{\circ}$ under the five levels of normal stress is shown in Figure 9. Under a normal stress of $0.5 \mathrm{MPa}$ or $1.0 \mathrm{MPa}$, the curve of shear expansion of NTJRM decreases with the increase of tangential displacement. This indicates that, under the action of tangential stress, the nonthrough jointed rock can overcome the suppression of normal stress and make the normal displacement decrease gradually. When the curve of shear expansion is below the abscissa, i.e., when the normal displacement is less than zero, under the action of shear force the NTJRM completely overcomes the action of normal stress.

When the normal stress is $1.5 \mathrm{MPa}, 2.0 \mathrm{MPa}$, and 3.0 $\mathrm{MPa}$, the curve of shear expansion of the NTJRM decreases gradually with the increase of tangential displacement. This also indicates that, under the action of tangential stress, the NTJRM overcomes the inhibition of normal stress and makes the normal displacement of the rock mass decrease gradually. However, the curves of shear expansion are all above the abscissa; that is, the normal displacement is greater than zero, which indicates that under the action of shear force the NTJRM cannot overcome the normal stress completely. By observing the curves of normal displacement and tangential displacement under various normal stress tests, it is found that the cracks formed in NTJRM are larger when normal stress is $0.5 \mathrm{MPa}$ or $1.0 \mathrm{MPa}$, but are smaller when normal stress is $1.5 \mathrm{MPa}, 2.0 \mathrm{MPa}$, or $3.0 \mathrm{MPa}$.

\subsection{Strength Characteristics of the Rock Specimens during the} Test. During the direct shear test of the NTJRM, the failure modes of the joint ends and rock bridges are observed, and the shear forces and corresponding tangential displacements during the failure are recorded. The internal system of the rock testing machine automatically recorded the curve of shear stress and shear displacement over time. And the external monitoring system recorded the time when the initial crack occurs. After the shear test, the shear stress and shear displacement recorded by the internal test system were found according to the time of initial crack generation provided by the external monitoring system. Then the initial crack strength of NTJRM can be determined according to the form of the tangential deformation curve. The initial fracture strength, peak strength, and residual strength of the NTJRM with three different relief angles of joints are presented in Tables 5-7.

3.2.1. The Peak Strength of the Rock Specimens. The peak strength of the NTJRM with serrated joints with undulation angles of $0^{\circ}, 15^{\circ}$, and $30^{\circ}$ is shown in Table 8 and Figure 10. It can be observed that the shear strength of the rock mass containing noncontinuous joints with the same joint surface morphology (the same undulation angle of joints) increases with the increase of normal stress. In addition, under the same normal stress, the shear strength of the NTJRM increases with the increase of the undulation angle of the serrated joints.

\subsubsection{Initial Fracture Strength of the Rock Specimens.} The data of the initial fracture strength of the rock mass under different normal stresses are sorted out to obtain the curve shown in Figure 11.

From Figures 10 and 11, it can be seen that the change trend of the initial fracture strength of the NTJRM with three different surface morphologies under different normal stresses is the same as that of the peak strength. When the joint surface morphology of all rock specimens was set to be the same in the test, the initial fracture strength increased with the increase of normal stress. When the normal stress was controlled to be consistent in the test, the initial fracture strength increased with the increase of the undulation angle of the serrated joints. According to Tables 5-7 and Figure 11, it can be observed that, under different normal stresses, the percentage of initial fracture strength and peak strength of the NTJRM is between $67.92 \%$ and $70.03 \%$ when the undulation angle is $0^{\circ}$. Additionally, the percentage ranges from $69.91 \%$ to $70.30 \%$ when the undulation angle is $15^{\circ}$ and from $71.49 \%$ to $72.85 \%$ when the undulation angle is $30^{\circ}$. From the above it can be seen that the ratio of the initial fracture strength to peak strength of the NTJRM with the three kinds of serrated joint surfaces is between $65 \% \sim 75 \%$.

3.2.3. Residual Strength of the Rock Specimens. The residual strengths of NTJRM containing serrated joints with relief angles of $0^{\circ}, 15^{\circ}$, and $30^{\circ}$ are shown in Tables 5-7. They are then sorted out and plotted in Figure 12. By comparing Figures 11 and 12, it can be seen that in this test the variation trend of the residual strength of the NTJRM with three kinds of surface morphologies under different normal stresses is the same as that of the peak strength. By comparing the experimental data, it can be found that, for the NTJRM with the same joint surface morphology, the residual strength increases with the increase of normal stress. Additionally, 


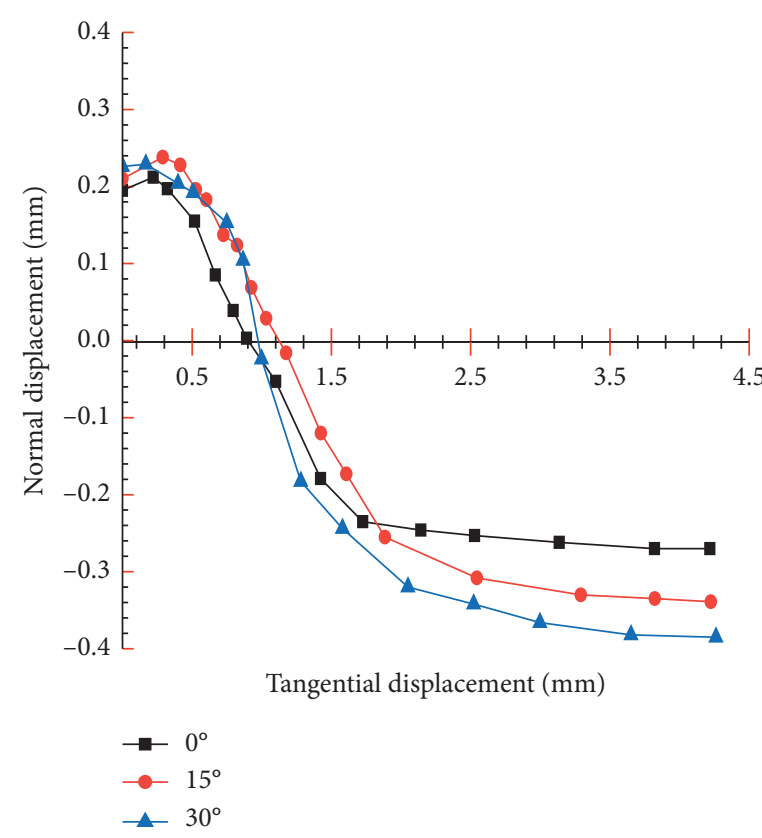

(a)

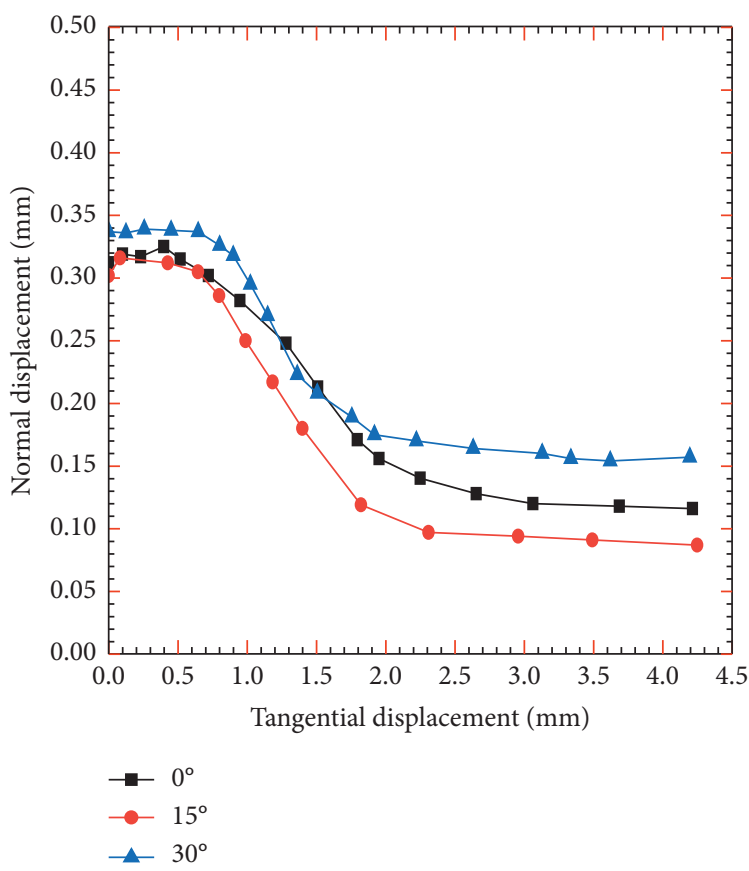

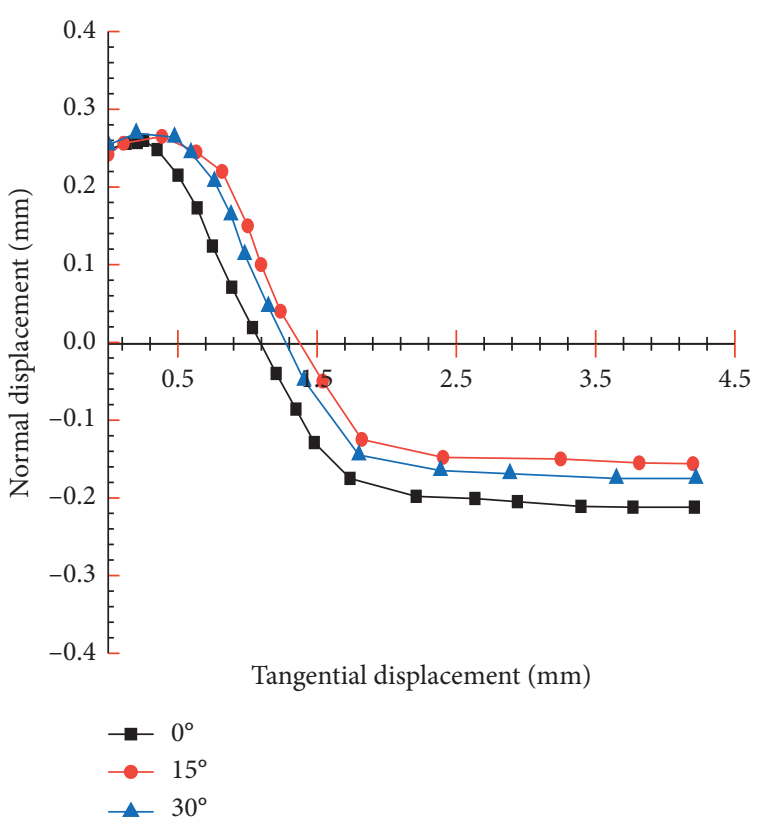

(b)

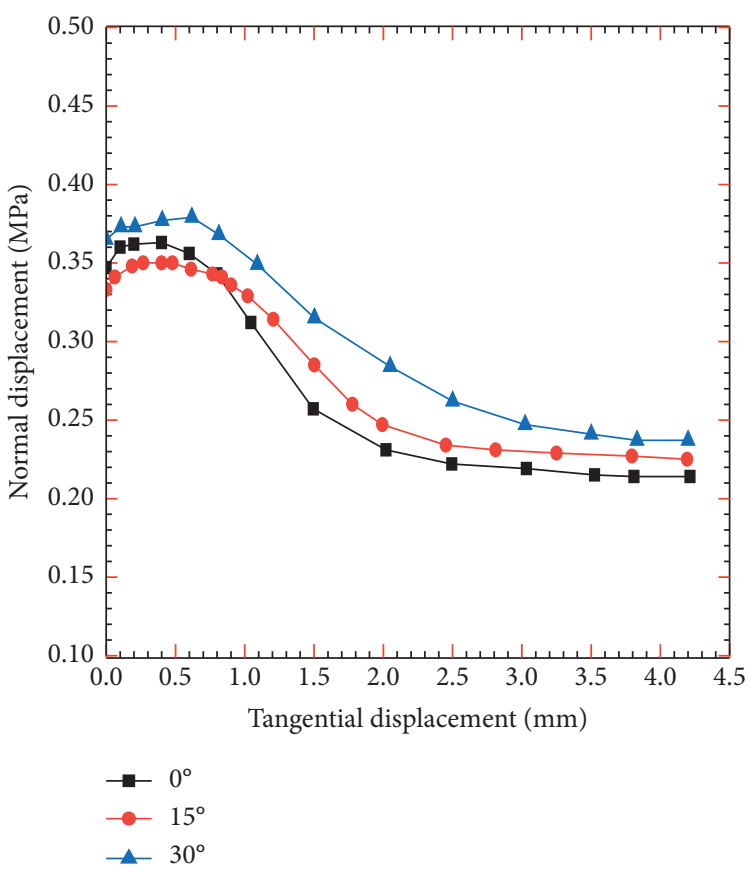

(d)

Figure 9: Continued. 


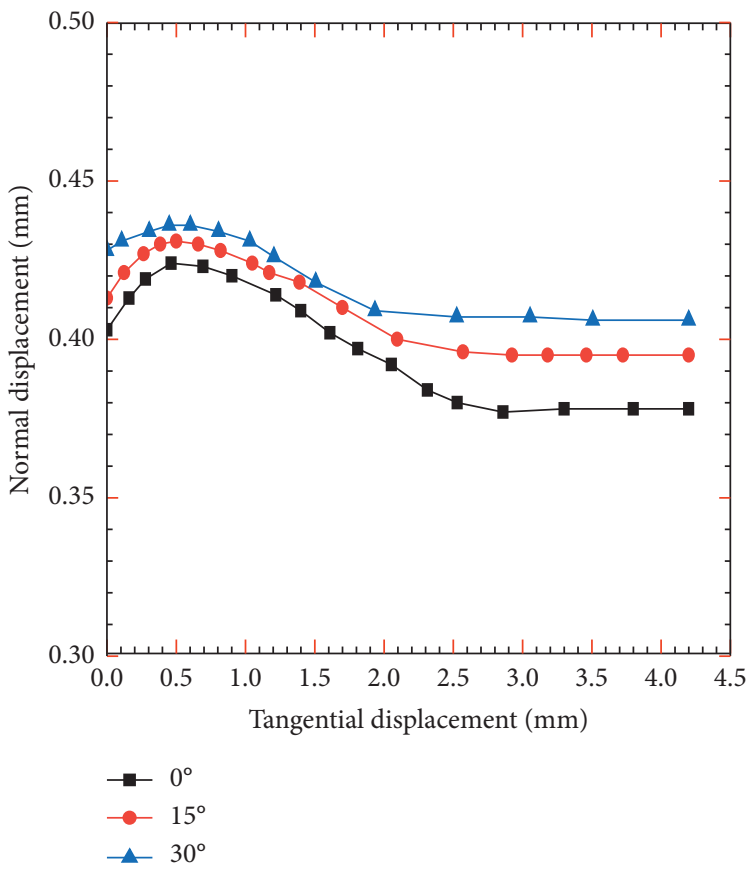

(e)

Figure 9: The shear dilatancy curve of the rock mass specimens (a) when the normal stress is $0.5 \mathrm{MPa}$, (b) when the normal stress is $1.0 \mathrm{MPa}$, (c) when the normal stress is $1.5 \mathrm{MPa}$, (d) when the normal stress is $2.0 \mathrm{MPa}$, and (e) when the normal stress is $3.0 \mathrm{MPa}$.

TABLE 5: Strength of some rock specimens $\left(\alpha=0^{\circ}\right)$.

\begin{tabular}{lccccc}
\hline \multirow{2}{*}{ Normal stress $(\mathrm{MPa})$} & Peak strength $\tau_{m}(\mathrm{MPa})$ & \multicolumn{2}{c}{ Initial fracture strength } & \multicolumn{2}{c}{ Residual strength } \\
& & $\tau_{0}(\mathrm{MPa})$ & Ratio to peak strength $(\%)$ & $\tau_{r}(\mathrm{MPa})$ & Ratio to peak strength (\%) \\
\hline 0.5 & 1.89 & 1.32 & 69.88 & 0.98 & 51.88 \\
1.0 & 2.18 & 1.53 & 70.03 & 1.36 & 62.23 \\
1.5 & 2.70 & 1.88 & 69.63 & 1.76 & 65.26 \\
2.0 & 2.98 & 2.03 & 68.24 & 2.35 & 78.86 \\
3.0 & 3.93 & 2.67 & 67.92 & 3.53 & 89.75 \\
\hline
\end{tabular}

TABLE 6: Strength of some rock specimens $\left(\alpha=15^{\circ}\right)$.

\begin{tabular}{lccccc}
\hline \multirow{2}{*}{ Normal stress $(\mathrm{MPa})$} & \multirow{2}{*}{ Peak strength $\tau_{m}(\mathrm{MPa})$} & \multicolumn{2}{c}{ Initial fracture strength } & \multicolumn{2}{c}{$\begin{array}{c}\text { Residual strength } \\
\text { Ratio to peak intensity (\%) }\end{array}$} \\
\hline 0.5 & 2.13 & 1.52 & 71.23 & 1.11 & 52.01 \\
1.0 & 2.53 & 1.81 & 71.30 & 1.45 & 57.05 \\
1.5 & 2.95 & 2.07 & 70.29 & 1.86 & 63.02 \\
2.0 & 3.62 & 2.54 & 70.22 & 2.80 & 77.43 \\
3.0 & 4.38 & 3.06 & 69.91 & 3.85 & 87.94 \\
\hline
\end{tabular}

TABLE 7: Strength of some of the specimens $\left(\alpha=30^{\circ}\right)$.

\begin{tabular}{lccccc}
\hline \multirow{2}{*}{ Normal stress $(\mathrm{MPa})$} & Peak strength $\tau_{m}(\mathrm{MPa})$ & \multicolumn{2}{c}{ Initial fracture strength } & \multicolumn{2}{c}{$\begin{array}{c}\text { Residual strength } \\
\text { Ratio to peak intensity (\%) }\end{array}$} \\
\hline 0.5 & 2.21 & 1.61 & 72.85 & 1.25 & 56.56 \\
1.0 & 2.98 & 2.15 & 72.25 & 1.75 & 58.92 \\
1.5 & 3.63 & 2.61 & 72.06 & 2.23 & 61.38 \\
2.0 & 3.99 & 2.86 & 71.72 & 3.00 & 75.31 \\
3.0 & 4.93 & 3.53 & 71.49 & 4.17 & 84.49 \\
\hline
\end{tabular}


TABLE 8: The peak strength of all rock mass specimens, unit: MPa.

\begin{tabular}{|c|c|c|c|}
\hline \multirow{2}{*}{ Normal stress (MPa) } & \multicolumn{3}{|c|}{ Undulation angle } \\
\hline & $0^{\circ}$ & $15^{\circ}$ & $30^{\circ}$ \\
\hline 0.5 & 1.89 & 2.13 & 2.19 \\
\hline 1.0 & 2.18 & 2.53 & 2.98 \\
\hline 1.5 & 2.70 & 2.95 & 3.63 \\
\hline 2.0 & 2.98 & 3.62 & 3.99 \\
\hline 3.0 & 3.93 & 4.38 & 4.93 \\
\hline
\end{tabular}

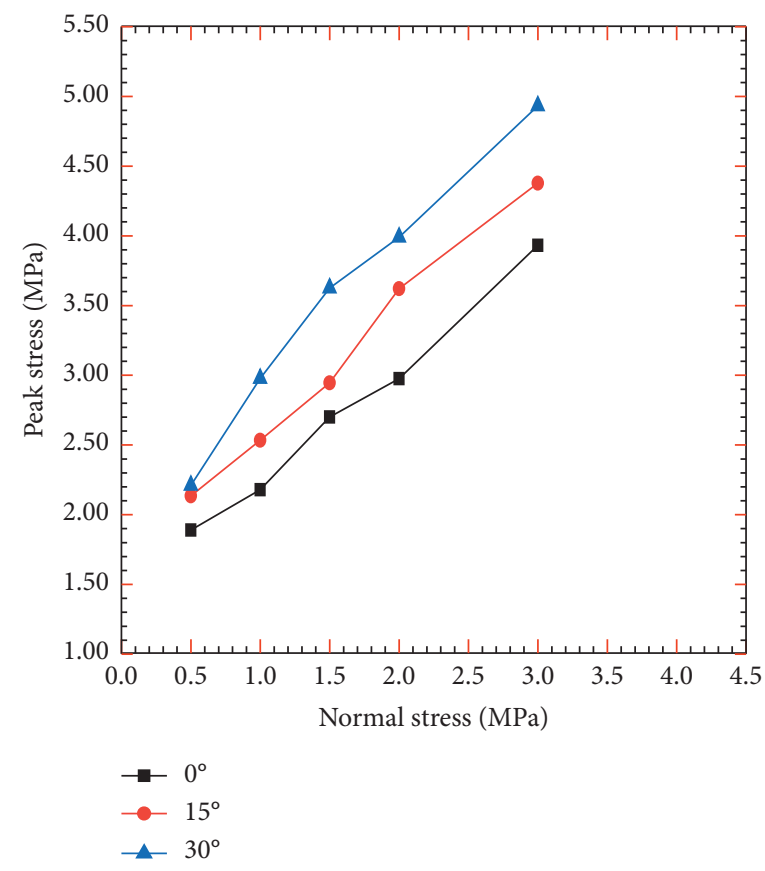

FIGURE 10: The peak strength of all rock mass specimens.

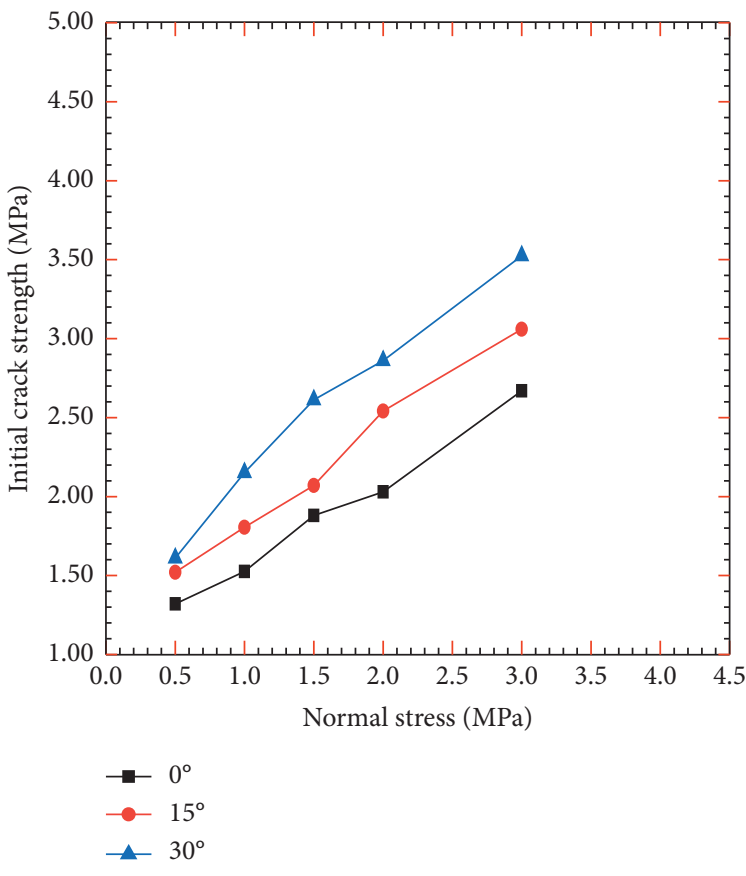

(a)

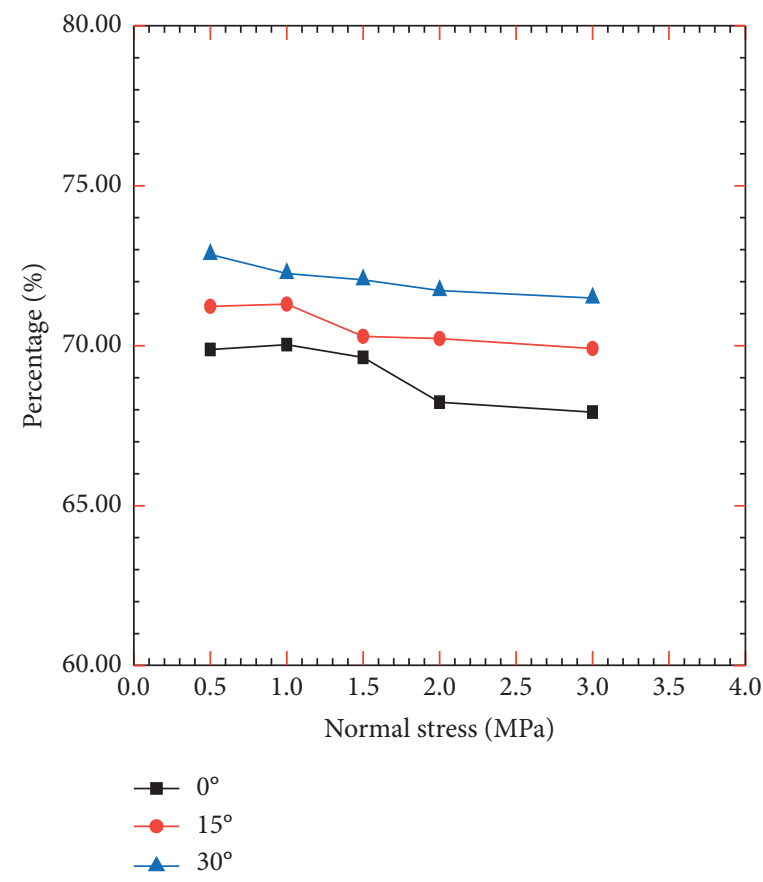

(b)

FIGURE 11: The initial crack strength of the specimens. (a) Initial fracture strength of specimens. (b) Ratio of the initial crack strength to peak strength. 


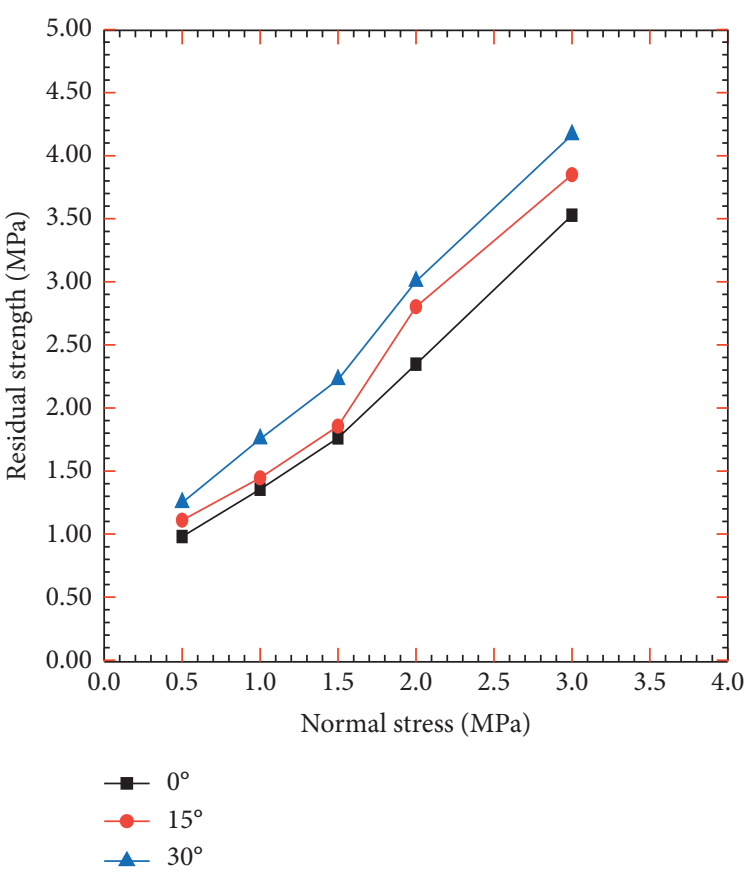

(a)

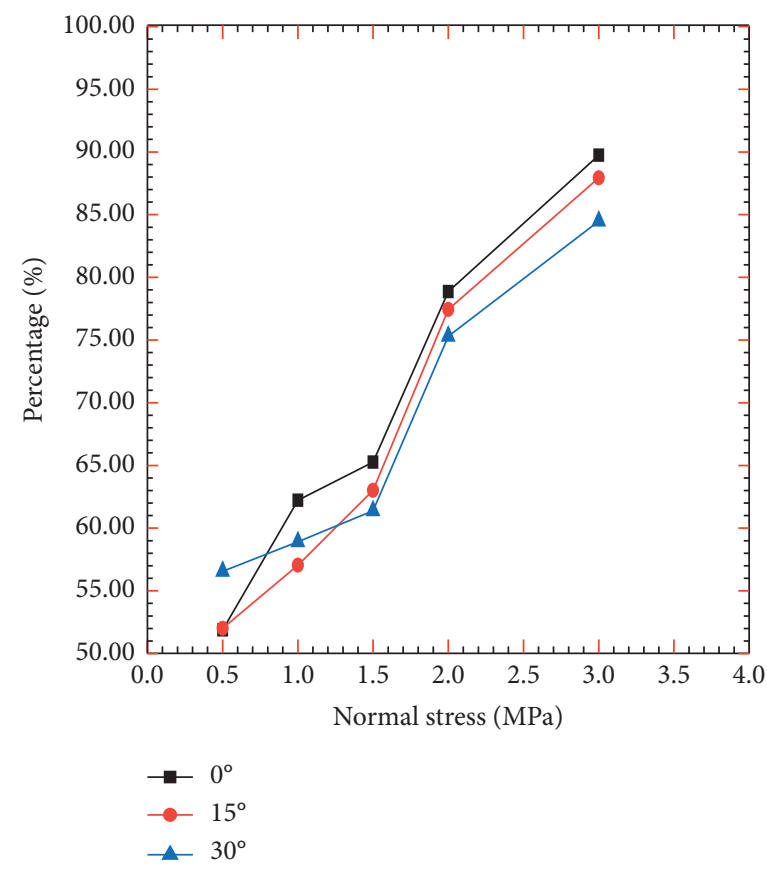

(b)

FIGURE 12: The residual strength of the NTJRM specimens. (a) Residual strength of specimens. (b) Ratio of the residual strength to peak strength.

under the same normal stress, the residual strength increases with the increase of the relief angle of the serrated joint. According to Tables 5-7 and Figure 12, under different normal stresses, the percentage of residual strength and peak strength of NTJRM is between $51.88 \%$ and $89.75 \%$ when the relief angle is $0^{\circ}$. Additionally, the percentage ranges from $52.01 \%$ to $87.94 \%$ when the undulation angle is $15^{\circ}$ and from $56.56 \%$ to $84.49 \%$ when the undulation angle is $15^{\circ}$. Therefore, the ratio of residual strength to peak strength of discontinuous jointed rock mass specimens with three kinds of serrated joint surfaces is between $50 \%$ and $90 \%$.

3.3. The Failure Modes of the Rock Bridges. The failure modes of rock mass with discontinuous joints can be divided into four types: TTTS, TSSS, TTTN, and SSSS [32]. Two failure modes, TTTS and TSSS, were observed in the tests. The failure mode is called TTTS mode in which the initial failure, expansion, and coalescence failure of the rock mass are all caused by the tensile action and the final coalescence surface is formed due to the shear action. The failure mode is called TSSS mode in which the initial failure of rock mass is caused by tensile action, while the expansion and final failure are caused by shear action, and the final coalescence surface is formed due to the shear action [32]. It can be found in the direct shear test under the normal stress of $1.0 \mathrm{MPa}$, the failure mode of rock specimens with joint undulation angle of $0^{\circ}$ is TTTS mode, as shown in Figure 13. In the direct shear test under the normal stress of 1.0 MPa, the failure mode of rock specimens with joint undulation angle of $30^{\circ}$ is TSSS mode, as shown in Figure 14, and when the normal stress is $1.5 \mathrm{MPa}$, the failure mode is also TSSS, as shown in Figure 15.

All the failure modes of rock specimens with different joint morphologies under different normal stresses are shown in Table 9. It can be seen from Table 9 that the failure modes of rock specimens with nonthrough joints in this test are TTTS and TSSS. The details are as follows:

(1) Under five levels of normal stress, the failure mode of rock mass specimens with undulation angle of $0^{\circ}$ is TTTS mode.

(2) The failure mode of rock mass specimens with undulation angle of $15^{\circ}$ is TTTS mode when the normal stress is less than 2.0 MPa, but it is TSSS mode when the normal stress is greater than or equal to $2.0 \mathrm{MPa}$.

(3) The failure mode of rock mass specimens with undulation angle of $30^{\circ}$ is TTTS mode when the normal stress is less than 1.0 MPa, but it is TSSS mode when the normal stress is greater than or equal to 1.0 MPa.

3.4. Analysis of Shear Strength Parameters. The peak shear strength of the three kinds of NTJRM specimens presented in Table 5 is plotted in Figure 16. According to Figure 16, the shear strength parameters of the rock mass specimens can be obtained by fitting, as shown in Table 10. It can be seen from Table 10 that the shear parameters cohesion and internal friction angle of rock mass with nonthrough joints increase with the increase of undulation angle of serrated joints.

In addition, the shear strength parameters of the specimens calculated according to Jennings' method [35] are given by 

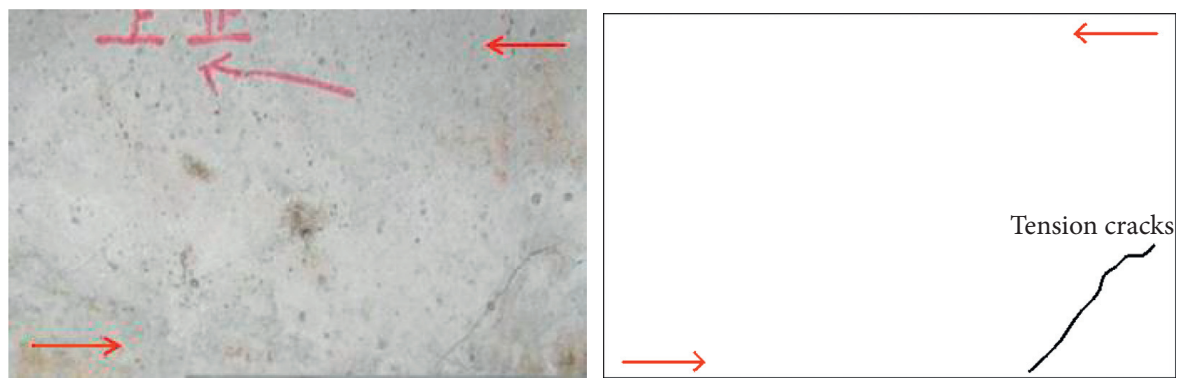

(a)
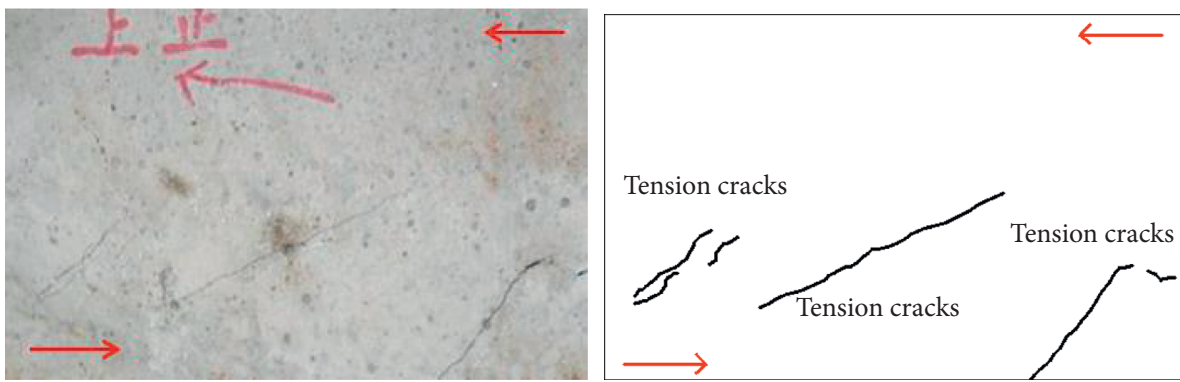

(b)
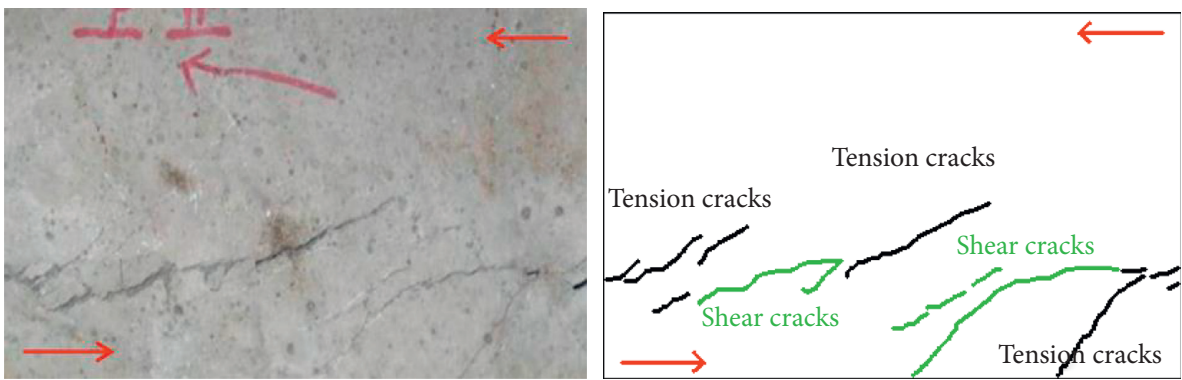

(c)

FIGURE 13: The failure modes of some of the rock specimens ( $\left.\sigma=1.0 \mathrm{MPa}, \alpha=0^{\circ}\right)$. (a) Initial failure. (b) Extended destruction. (c) Transfixion failure.
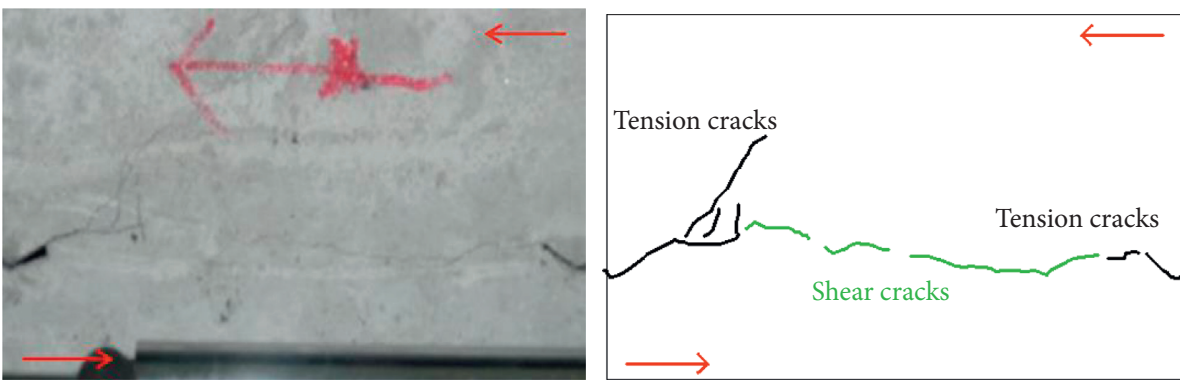

(a)
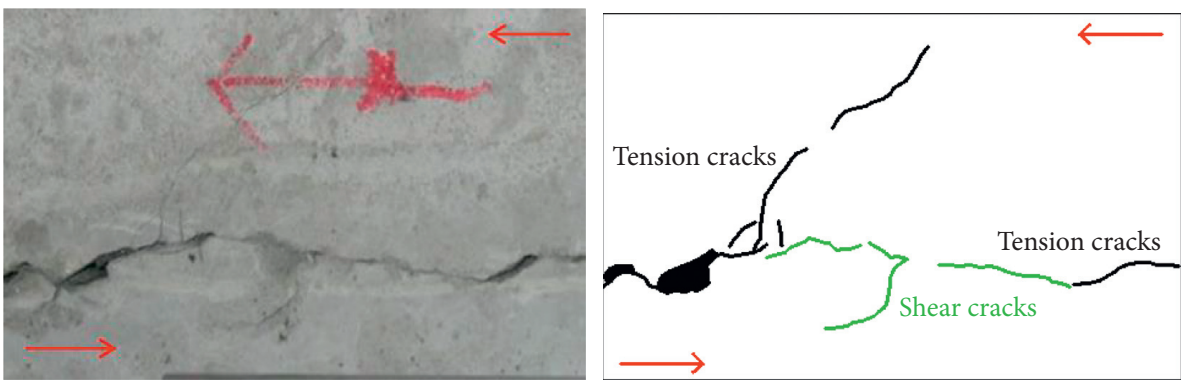

(b)

Figure 14: Continued. 

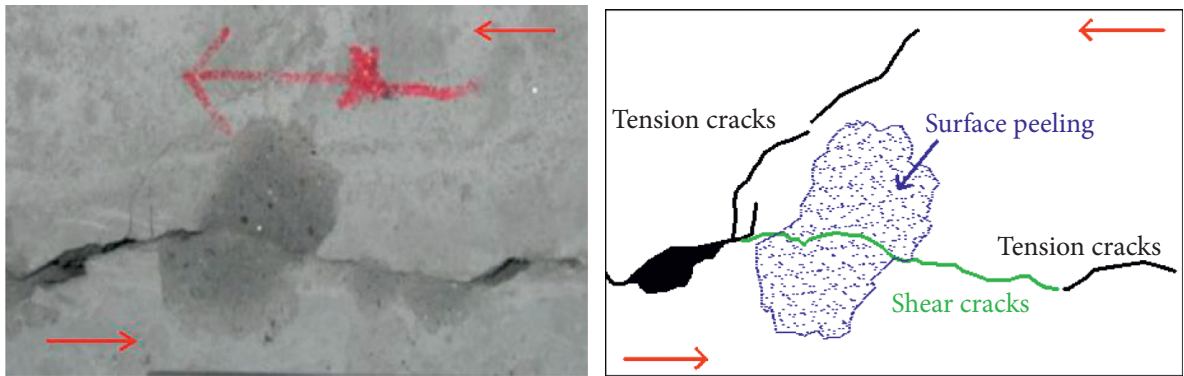

(c)

Figure 14: The failure modes of some of the rock specimens $\left(\sigma=1.0 \mathrm{MPa}, \alpha=30^{\circ}\right)$. (a) Initial damage. (b) Extended destruction. (c) Transfixion failure.
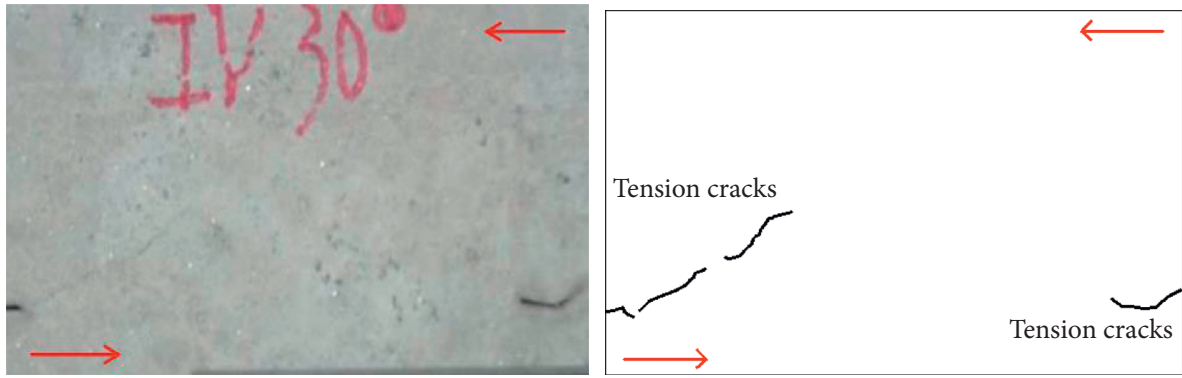

(a)
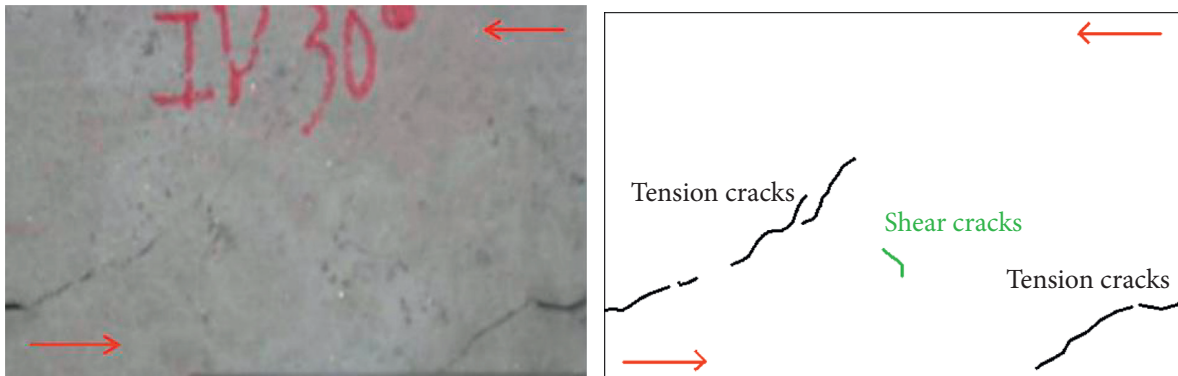

(b)
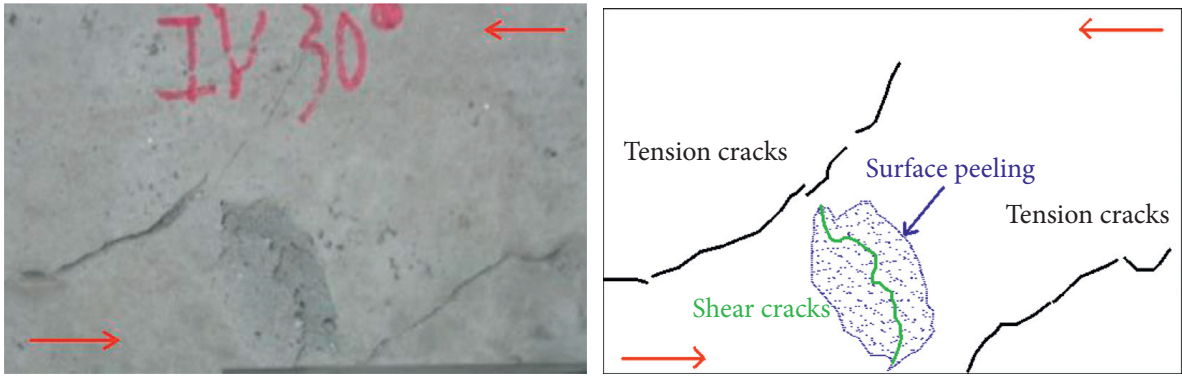

(c)

Figure 15: The failure modes of some of the rock specimens ( $\left.\sigma=1.5 \mathrm{MPa}, \alpha=30^{\circ}\right)$. (a) Initial failure. (b) Extended destruction. (c) Transfixion failure. 
TABLE 9: The failure modes of all the rock mass specimens.

\begin{tabular}{lcccc}
\hline \multirow{2}{*}{ Undulation angle of joints } & \multicolumn{3}{c}{ Normal stress (MPa) } \\
& 0.5 & 1.0 & 1.5 & 2.0 \\
\hline $0^{\circ}$ & TTTS & TTTS & TTTS & TTTS \\
$15^{\circ}$ & TTTS & TTTS & TTTS & TSSS \\
$30^{\circ}$ & TTTS & TSSS & TSSS & TSSS \\
\hline
\end{tabular}

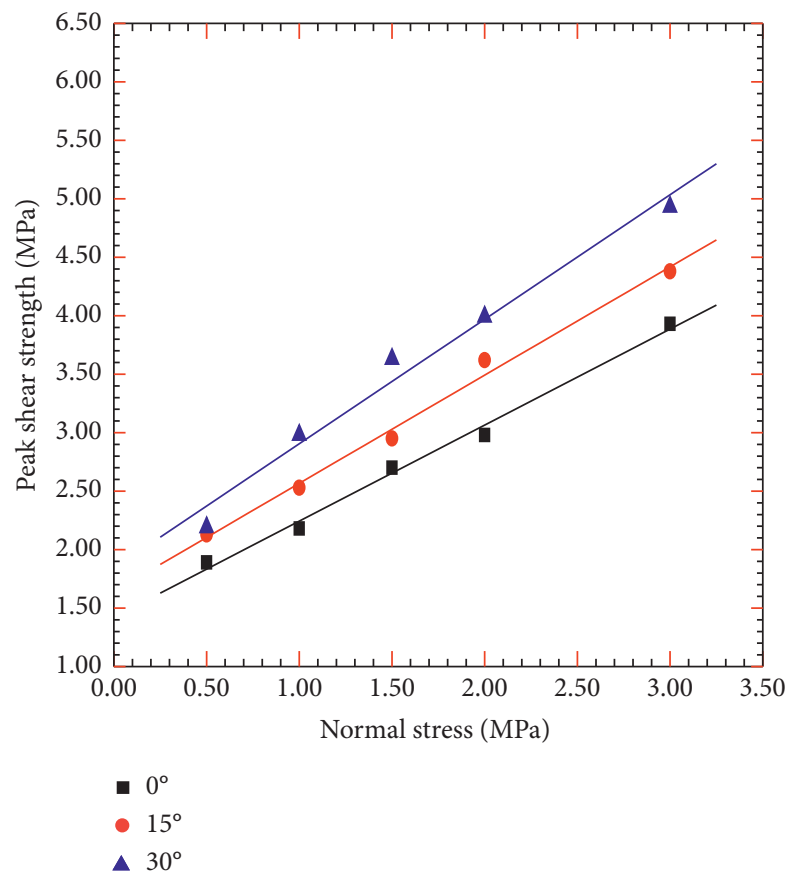

FIgURE 16: Peak shear strength of the rock mass specimens.

TABLE 10: Shear parameters results obtained through tests and calculations.

\begin{tabular}{lcr}
\hline The angle of joint relief & \multicolumn{2}{c}{ The fitted value of the test results } \\
& Cohesion $(\mathrm{MPa})$ & Angle of internal friction $\left({ }^{\circ}\right)$ \\
\hline $0^{\circ}$ & 1.42 & 39.4 \\
$15^{\circ}$ & 1.64 & 42.8 \\
$30^{\circ}$ & 1.84 & 46.8 \\
\hline
\end{tabular}

TABLE 11: Shear parameters results obtained through Jennings.

\begin{tabular}{lcr}
\hline The angle of joint relief & \multicolumn{2}{c}{ The fitted value of the test results } \\
Angle of internal friction $\left({ }^{\circ}\right)$
\end{tabular}

$$
\begin{aligned}
c & =k c_{j}+(1-k) c_{b}, \\
\tan \phi & =k \tan \phi_{j}+(1-k) \tan \phi_{b}, \\
\varphi & =\arctan \varphi
\end{aligned}
$$

where $c$ is cohesion of rock mass with discontinuous joints, $\varphi_{j}$ is internal friction angle, $k$ is joint connectivity, $c_{j}$ is joint cohesion of rock mass with discontinuous joints, $\varphi_{j}$ is internal friction angle of joint, $c_{b}$ is cohesion of rock bridge, and $\varphi_{b}$ is internal friction angle of rock bridge.

The parameters of shear strength of the NTJRM specimens calculated by Jennings' method are listed in Table 11.

It can be seen from Tables 10 and 11 that the cohesion calculated by Jennings' method is greater than by test fitting. 
Except the fluctuation angle $0^{\circ}$, the internal friction angle calculated by Jennings' method is larger than that fitted by experiment. In a word, the shear strength of the rock mass with discontinuous joints calculated by Jennings' method will be greater than the actual experimental results.

\section{Conclusions}

Direct shear tests of nonthrough jointed rock masses with three kinds of morphologies joints are carried out under five levels of normal stress. The main conclusions are as follows:

(1) Under the same normal stress, the normal displacement and the peak tangential displacement increase with the increase of undulation angle.

(2) The joint morphology has influence on the strength characteristics of rock mass with discontinuous joints. Under the same normal stress, the shear strength, initial crack strength, and residual strength of rock mass with nonthrough joints increase with the increase of undulation angle.

(3) The failure mode of rock mass with discontinuous joints is related to the joint morphology and normal stress. Under the same normal stress, the rock mass with low undulation angle is prone to failure in TTTS mode, and the rock mass with high undulation angle is prone to failure in TSSS mode.

(4) The shear parameters calculated by Jennings' method are larger than those fitted by experiments. The shear strength of the rock mass with discontinuous joints calculated by Jennings' method will be greater than the actual experimental results.

\section{Data Availability}

The data which support the findings of this study are available within this article.

\section{Conflicts of Interest}

The authors declare that they do not have any commercial or associative interest that represents conflicts of interest in connection with this work.

\section{Acknowledgments}

This work was supported by the National Natural Science Foundation Project (11562005), the First Class Discipline Construction Project of Civil Engineering in Guizhou Province (QYNYL [2017] 0013), the Natural Science Foundation of Guizhou Province (qkeheji [2019] No. 1057), and Major Scientific and Technological Projects of Guizhou Province (Qiankehe major special project [2018] 3011).

\section{References}

[1] H. K. Singh and A. Basu, "A comparison between the shear behavior of "real" natural rock discontinuities and their replicas," Rock Mechanics and Rock Engineering, vol. 51, no. 1, pp. 329-340, 2018.
[2] J. B. Zhu, H. Li, and J. H. Deng, "A one-dimensional elastoplastic model for capturing the nonlinear shear behaviour of joints with triangular asperities based on direct shear tests," Rock Mechanics and Rock Engineering, vol. 52, no. 6, pp. 1671-1687, 2018.

[3] K. Zhang, Y. Chen, W. Fan, X. Liu, H. Luan, and J. Xie, "Influence of intermittent artificial crack density on shear fracturing and fractal behavior of rock bridges: experimental and numerical studies," Rock Mechanics and Rock Engineering, vol. 53, no. 2, pp. 553-568, 2019.

[4] Y. T. Wang, X. P. Zhou, and Y. D. Shou, "The modeling of crack propagation and coalescence in rocks under uniaxial compression using the novel conjugated bond-based peridynamics," International Journal of Rock Mechanical and Sciences, vol. 128, 2017.

[5] Z. B. Guo, J. Y. Fan, F. N. Wang, H. B. Zhou, and W. Li, "Geomechanical model experiment study on deformation and failure mechanism of the mountain tunnel in layered jointed rock mass," Advances in Civil Engineering, vol. 2021, Article ID 6645124, , 2021.

[6] Q. B. Lin, P. Cao, J. J. Meng, R. H. Cao, and Z. Y. Zhao, "Strength and failure characteristics of jointed rock mass with double circular holes under uniaxial compression: insights from discrete element method modelling," Theoretical and Applied Fracture Mechanics, vol. 109, Article ID 102692, 2020.

[7] Q. B. Lin, P. Cao, Y. Z. Liu, R. H. Cao, and J. T. Lia, "Mechanical behaviour of a jointed rock mass with a circular hole under compression-shear loading: experimental and numerical studies," Theoretical and Applied Fracture Mechanics, vol. 114, Article ID 102998, 2021.

[8] F. Xiang, Z. J. Yang, and K. Li, "Effects of the lining structure on mechanical and fracturing behaviors of four-arc shaped tunnels in a jointed rock mass under uniaxial compression," Theoretical and Applied Fracture Mechanics, vol. 112, Article ID 102887, 2021.

[9] A. Bobet and H. H. Einstein, "Fracture coalescence in rocktype materials under uniaxial and biaxial compression," International Journal of Rock Mechanics and Mining Sciences, vol. 35, no. 7, pp. 863-888, 1998.

[10] R. H. C. Wong and K. T. Chau, "Crack coalescence in a rocklike material containing two cracks," International Journal of Rock Mechanics and Mining Sciences, vol. 35, no. 2, pp. 147-164, 1998.

[11] S. P. Morgan and H. H. Einstein, "Cracking processes affected by bedding planes in opalinus shale with flaw pairs," Engineering Fracture Mechanics, vol. 176, pp. 213-234, 2017.

[12] M. Alneasan, M. Behnia, and R. Bagherpour, "Analytical investigations of interface crack growth between two dissimilar rock layers under compression and tension," Engineering Geology, vol. 259, Article ID 105188, 2019.

[13] D.-J. Wang, H. Tang, D. Elsworth, and C. Wang, "Fracture evolution in artificial bedded rocks containing a structural flaw under uniaxial compression," Engineering Geology, vol. 250, pp. 130-141, 2019.

[14] R. H. Cao, H. Lin, Q. B. Lin, and J. Meng, "Failure mechanism of non-persistent jointed rock-like specimens under uniaxial loading: laboratory testing," International Journal of Rock Mechanics and Mining Sciences, vol. 132, pp. 147-164, Article ID 104341, 2020.

[15] R. H. Cao, R. B. Yao, T. Hu, C. S. Wang, H. Li, and J. J. Meng, "Failure and mechanical behavior of transversely isotropic rock under compression-shear tests: laboratory testing and numerical simulation," Engineering Fracture Mechanics, vol. 2020, Article ID 107389, 2020. 
[16] C. Y. Zhang, Y. X. Wang, and T. T. Jiang, "The propagation mechanism of an oblique straight crack in a rock sample and the effect of osmotic pressure under in-plane biaxial compression," Arabian Journal of Geosciences, vol. 13, no. 15, Article ID 736, 2020.

[17] Q. B. Lin, P. Cao, G. P. Wen, J. J. Meng, R. H. Cao, and Z. Y. Zhao, "Crack coalescence in rock-like specimens with two dissimilar layers and pre-existing double parallel joints under uniaxial compression," International Journal of Rock Mechanics and Mining Sciences, vol. 139, Article ID 104621, 2021.

[18] Q. B. Lin, P. Cao, R. H. Cao, H. Lin, and J. J. Meng, "Mechanical behavior around double circular openings in a jointed rock mass under uniaxial compression," Archives of Civil and Mechanical Engineering, vol. 20, 2020.

[19] X. Fan, X. Jiang, Y. Liu, H. Lin, and Z. He, "Local stress distribution and evolution surrounding flaw and opening within rock block under uniaxial compression," Theoretical and Applied Fracture Mechanics, vol. 112, Article ID 102941, 2021.

[20] G. Wang, Y. Zhang, Y. Jiang, S. Wang, and W. Jing, "Macromicro failure mechanisms and damage modeling of a bolted rock joint," Advances in Materials Science and Engineering, vol. 2017, Article ID 1627103, , 2017.

[21] C. Zhao, Y. M. Zhou, C. F. Zhao, and C. Bao, "Cracking processes and coalescence modes in rock-like specimens with two parallel pre-existing cracks," Rock Mechanics and Rock Engineering, vol. 51, no. 11, pp. 3377-3393, 2018.

[22] E. Z. Lajtai, "Strength of discontinuous rocks in direct shear," Géotechnique, vol. 19, no. 2, pp. 218-233, 1969.

[23] E. Z. Lajtai, "Shear strength of weakness planes in rock," International Journal of rock mechanics and mining sciences abstract, vol. 6, no. 7, pp. 499-515, 1969.

[24] G. Q. Chen, J. C. Wang, W. Wang, F. Y. Luo, and Z. B. Li, "Failure characteristics of rock mass with intermittent joints of different connecting rates under direct shear test," Journal of Engineering Geology, vol. 25, no. 2, pp. 322-329, 2017.

[25] C. A. Qin, G. Q. Chen, H. J. Zheng, and P. Tang, "Failure of rock bridge at the end and fracture condition under direct shear tests," Rock and Soil Mechanics, vol. 25, no. 2, pp. 642-652, 2019.

[26] S. Heng, X. Z. Li, X. Liu, and X. D. Zhang, "Study on the propagation mechanisms of shale fractures under direct shear conditions," Journal of rock mechanics and engineering, vol. 25, no. 2, pp. 2438-2450, 2019.

[27] W. Zhao, R. Huang, and M. Yan, "Study on the deformation and failure modes of rock mass containing concentrated parallel joints with different spacing and number based on smooth joint model in PFC," Arabian Journal of Geosciences, vol. 8, no. 10, pp. 7887-7897, 2015.

[28] P. Wang, T. Yang, T. Xu, M. Cai, and C. Li, "Numerical analysis on scale effect of elasticity, strength and failure patterns of jointed rock masses," Geosciences Journal, vol. 20, no. 4, pp. 539-549, 2016.

[29] Q. Z. Chen, Y. S. Zhang, Y. M. Liu, W. Wang, and K. Cao, "Influence of joint undulation angle on mechanical properties of non-penetrated joint rock mass," Journal of Underground Space and Engineering, vol. 16, no. 2, pp. 351-358, 2020.

[30] P. Wang, F. Ren, and M. Cai, "Influence of joint geometry and roughness on the multiscale shear behaviour of fractured rock mass using particle flow code," Arabian Journal of Geosciences, vol. 13, no. 4, p. 165, 2020.

[31] M. H. Ma, F. H. Ren, and W. S. Liu, "Experimental investigation on shear failure mechanism of rock mass with intermittent joints," Advances in Civil Engineering, vol. 2021, Article ID 6623148, 10 pages, 2021.

[32] Y. M. Liu and C. C. Xia, "Weakening mechanism of mechanical behaviors and failure model of rock mass containing discontinuous joints under direct shear condition," Rock and Soil Mechanics, vol. 31, no. 3, pp. 695-701, 2010.

[33] Y. M. Liu, J. Liu, and C. C. Xia, "Research on strength behavior of rock mass containing discontinuous joints by direct shear test under different joint surface morphologies," Rock and Soil Mechanics, vol. 35, no. 5, Article ID 12691274, 2014.

[34] Q. Z. Chen, Y. M. Liu, and S. Y. Pu, "Strength characteristics of nonpenetrating joint rock mass under different shear conditions," Advances in Civil Engineering, vol. 2020, Article ID 3579725, 13 pages, 2020.

[35] H. H. Einsten, D. Veneziano, G. B. Baecher, and K. J. O’Reilly, "The effect of discontinuity persistence on rock slope stability," International Journal of Rock Mechanics and Mining Science \& Geomechanics Abstracts, vol. 20, no. 5, pp. 227-236, 1983. 